УДК 517.9

\title{
The Characteristics of Observation of the Non-uniform Magnetization on the Surface of the Thin Magnetic Films in $\mathrm{Ta} / \mathrm{CoFeB} / \mathrm{MgO} / \mathrm{CoFeB} / \mathrm{Ta}$ Multilayers
}

\author{
Nikolay A.Djuzhev \\ Anatoly F.Popkov \\ Maksim A. Makhiboroda \\ Gleb D. Demin \\ Aleksandr M. Kozmin \\ Maksim Y. Chinenkov* \\ National Research University of Electronic Technology (MIET) \\ Shokina sq., bld. 1, Moscow, Zelenograd, 124498
}

Russia

Received 20.08.2016, received in revised form 10.10.2016, accepted 14.11.2016

\begin{abstract}
This work presents the results of the study of non-uniformly magnetized regions on the surface of thin magnetic films in multilayer magnetic tunnel junction (MTJ) structure $\mathrm{Ta} / \mathrm{CoFeB} / \mathrm{MgO} / \mathrm{CoFeB} / \mathrm{Ta}$ observed by highly sensitive magnetic force microscopy (MFM) probes. The micromagnetic simulation of the magnetization dynamics in CoFeB magnetic layer after the application of the external magnetic field of $0.5 \mathrm{~T}$ is conducted using mumax3 open-source software. The areas of the existence of magnetic vortices and domain walls in $\mathrm{CoFeB}$ magnetic film are found where the domain wall thickness was measured by $M F M$ in the nanometer scale.
\end{abstract}

Keywords: magnetic force microscopy, thin magnetic films, magnetic domains, magnetic tunnel junction. DOI: $10.17516 / 1997-1397-2017-10-1-40-44$.

\section{Introduction}

Despite the fact that the scanning probe microscopy (SPM) has the broadest range of applications in many modern studies, the method of dynamic MFM is currently used for imaging of magnetic fields linear dimensions greatly exceed the nanometer scale. First of all, this is due to the technological features of the scanning processes by SPM and the lack of the corresponding samples required for the observation of nanoscale effects. The impossibility of applying an external magnetic field to rearrange the domain walls on the sample surface during MFM imaging also remains an obstacle to the transition in the nanometer range of magnetic measurements.

\section{The experimental technique}

The constant magnetic field was applied to the test sample of multilayer thin-film MTJ structure $\mathrm{Ta} / \mathrm{CoFeB} / \mathrm{MgO} / \mathrm{CoFeB} / \mathrm{Ta}$ for the detection and study of the gradient of magnetic

\footnotetext{
*chinenkov@inbox.ru

(C) Siberian Federal University. All rights reserved
} 
force on its surface. In the process of MFM measurements on the submicron level, it is necessary to separate the magnetic image from the topography of the sample. To solve this problem, the magnetic imaging was carried out based on the two-pass technique of dynamic MFM. In the first pass the sample topography was determined using the standard intermittent-contact method of SPM. During the second pass the cantilever oscillating at the resonant frequency was used for the detecting the magnetic field. By means of the feedback system in the second pass, the distance between the scanned surface and the fixed cantilever tip is kept constant and the magnetic image was obtained for the sample topography scanned in the first pass. The tip-surface distance must be large enough to neglect van der Waals forces and to expose the cantilever by only the long-range magnetic force in the second pass. In accordance with this method, as the sample topography as its magnetic image can be scanned successively for the same surface area.

\section{The micromagnetic simulation}

Using the micromagnetic GPU-accelerated software mumax3 [1], the micromagnetic simulation of the formation of domain walls in the bottom $\mathrm{CoFeB}$ layer of thin-film MTJ structure after the switching off the magnetic field applied perpendicular to the sample surface was carried out which corresponds to the experiment described below in our work. The parameters of $\mathrm{CoFeB}$ magnetic film were set as follows: the exchange stiffness constant $A_{E X}=13 \cdot 10^{-12} \mathrm{~J} / \mathrm{m}$, the saturation magnetization $M_{S}=9.57 \cdot 10^{5} \mathrm{~A} / \mathrm{m}$, the Gilbert damping parameter $\alpha=0.02$. The micromagnetic dynamics of the magnetic system can be described by the Landau-Lifshitz-Gilbert equation

$$
\frac{d \mathbf{M}}{d t}=-\gamma \mathbf{M} \times \mathbf{B}_{e f f}+\frac{\alpha}{M_{S}} \mathbf{M} \times \frac{d \mathbf{M}}{d t},
$$

where $\gamma$ is the gyromagnetic ratio, $\mathbf{M}$ is the magnetization of $\mathrm{CoFeB}$ magnetic layer, $\mathbf{B}_{e f f}=\mathbf{B}+\mathbf{B}_{e x}+\mathbf{B}_{u}+\mathbf{B}_{d}$ is the effective magnetic field, including the external magnetic field $\mathbf{B}$, the exchange field $\mathbf{B}_{e x}$, the anisotropy field $\mathbf{B}_{u}$ and the demagnetization field $\mathbf{B}_{d}$. The magnetic field of $0.5 \mathrm{~T}$ was applied to the structure during $3 \mathrm{~ns}$, after which it was switched off for the time $(\sim 3 \mathrm{~ns})$ needed to ensure that the magnetic state of $\mathrm{CoFeB}$ layer comes into equilibrium. Fig. 1a shows the time dependence of the components of normalized magnetization $\mathbf{m}=\left(m_{X}, m_{Y}, m_{Z}\right)$ illustrating the rotation of the magnetization vector out of the plane under the transverse magnetic field and its subsequent relaxation to the initial state in the plane of the layers.

The micromagnetic interpretation of the MFM measurement was also theoretically obtained and the scanned area of the sample is $610 \mathrm{~nm} \times 610 \mathrm{~nm}$, the height of the magnetic tip $\mathrm{h}=20 \mathrm{~nm}$, the distance from the tip to the sample surface $d=20 \mathrm{~nm}$ as it was set in the experiment. Both micromagnetic and simulated MFM image of the magnetic layer of MTJ structure after the switching of the magnetic field are presented at Fig. 1b-c where the estimated thickness of domain wall in the center area is about $25 \mathrm{~nm}$ which is consistent with experimental data shown below. From Fig. 1 it is easy to see the formation of a magnetic vortex in the center of the scanned area in which the magnetization is perpendicular to the plane of the layers, where the region itself is divided into four magnetic domains separated by thin magnetic walls as presented at MFM image of $\mathrm{CoFeB}$ magnetic layer. 

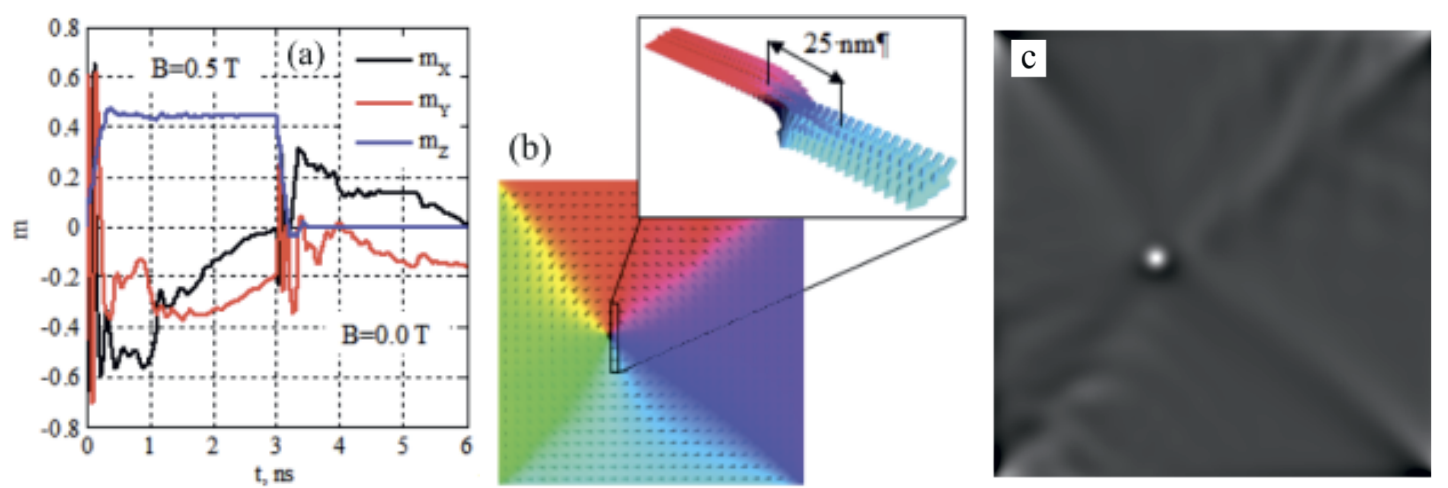

Fig. 1. a) The time dependence of the magnetization components in CoFeB magnetic layer: the magnetic field with amplitude of $0.5 \mathrm{~T}$ is applied perpendicular to the layer for $3 \mathrm{~ns}$ after which it turns off. (b) Micromagnetic and (c) simulated MFM images of the magnetic surface of CoFeB magnetic layer in MTJ structure generated by mumax3 after switching off the magnetic field. The calculated thickness of domain wall is about $25 \mathrm{~nm}$

\section{The experimental results and discussion}

In this paper we study the magnetic properties of thin magnetic films of MTJ structure in the absence of an external magnetic field and under its application to the sample with the amplitude of $0.5 \mathrm{~T}$ using the scanning probe microscope Smart-SPM 1000 (manufactured by AIST-NT, Zelenograd). The test samples of multilayer MTJ structure were obtained using AJA ATC 2200 UHV rf magnetron sputtering system. First, the Si3N4 layer was formed on the prepared silicon substrate, whereupon $\mathrm{Ta}(40 \mathrm{~nm}), \mathrm{CoFeB}(9 \mathrm{~nm}), \mathrm{MgO}(2 \mathrm{~nm}), \mathrm{CoFeB}(3 \mathrm{~nm})$ and Ta $(10$ $\mathrm{nm}$ ) layers were sequentially deposited on the Si-Si3N4 bilayer. The materials in the multilayer structure correspond to the MTJ composition usually used in the experiments of the study of tunneling magnetoresistive effect [4]. During the measurement, the MFM images of the magnetic surface of the multilayer MTJ structure were obtained in the absence of magnetic field (Fig. 2a) and after its applying with the amplitude of $0.5 \mathrm{~T}$ perpendicularly to the bottom layer of the sample (Fig. 2b).

The measurements were performed in normal conditions in air, where highly sensitive MFM probes HR-MFM were used (manufactured by Team-Nanotec, Germany). The curvature radius of the cantilever tips with magnetic coating was controlled within $20 \mathrm{~nm}$ using scanning electron microscopy (SEM). The amplitude of the cantilever oscillations was set about $30 \mathrm{~nm}$. The distance between the sample surface and the cantilever tip does not exceed $20 \mathrm{~nm}$. It can be seen that the applied magnetic field causes the eddy rearrangement of magnetic domains in local areas on the magnetic surface of $\mathrm{CoFeB}$ in MTJ structure. The magnetic domain walls in the absence of magnetic field are absent or not clearly visible at Fig. 2a, even with the double increase in the measurement area. As it is shown in Fig. 2b, we also estimated the value of the differential gradient of magnetic forces at the sample surface, in this case it is about $20 \mathrm{~nm}$.

\section{Conclusion}

In this paper we demonstrated the possibility of the measurement of the domain wall thickness of nanometer scale by MFM magnetic probes in air. The processes of the magnetic reconstruction 

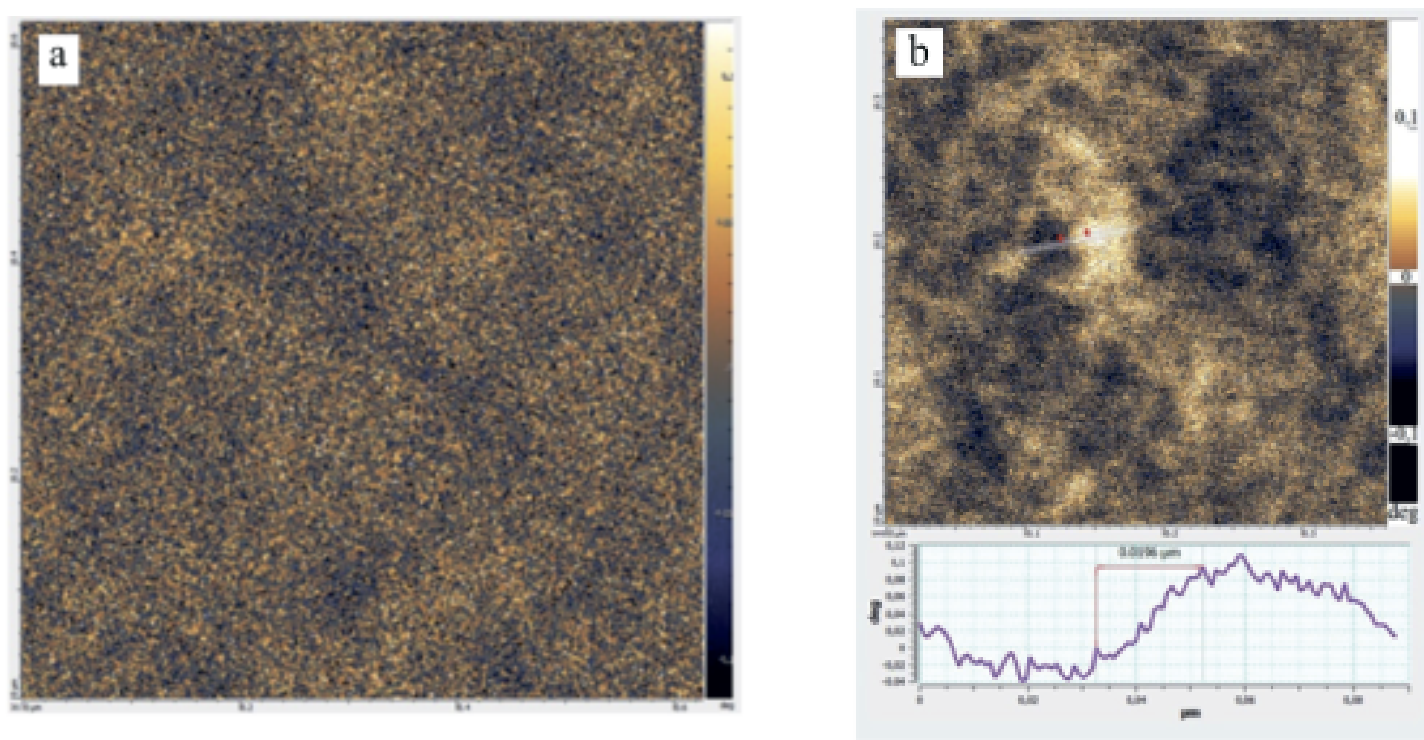

Fig. 2. MFM image of the sample surface (a) in the absence of magnetic field where the domain walls are not clearly visible and (b) after applying the magnetic field of $0.5 \mathrm{~T}$, where the measured thickness of domain wall is about $20 \mathrm{~nm}$

of domain walls in $\mathrm{CoFeB}$ magnetic layer under the applied magnetic field were also theoretically studied.

This work was supported by the RF Ministry of Education and Science contract № 14.578.21.0007 (RFMEFI57814X0007) and conducted using the equipment of Multi-access center "Microsystem technics and electronic component base" MIET.

\section{References}

[1] A.Vansteenkiste, J.Leliaert, M.Dvornik, M.Helsen, F.Garcia-Sanchez, B.V.Waeyenberge, The design and verification of MuMax3, AIP Advances, 4(2014), 107-133.

[2] A.G.Temiryazev, S.A.Saunin, V.E.Sizov, M.P.Temiryazeva, Magnitnaya silovaya mikroskopiya issledovaniya domennyh struktur $\mathrm{v}$ magnitnyh plenkah (Magnetic force microscopy study of domain structures in magnetic films), Bull. Ross. Akad. Nauk, Fizika, 78(2014), no. 1, 49-52 (in Russian).

[3] N.A.Djuzhev, A.M.Kozmin, M.Yu.Chinenkov, Specific features of observing magnetization inhomogeneities on the surface of permalloy thin films by means of highly sensitive magneticforce-microscopy probes, Journal of Surface Investigation. X-ray, Synchrotron and Neutron Techniques, 10(2016), no. 1, 39-42.

[4] W.X.Wang, Y.Yang, H.Naganuma, Y.Ando, R.C. Yu, X.F.Han, The perpendicular anisotropy of $\mathrm{Co}_{40} \mathrm{Fe}_{40} \mathrm{~B}_{20}$ sandwiched between $\mathrm{Ta}$ and $\mathrm{MgO}$ layers and its application in $\mathrm{CoFeB} / \mathrm{MgO} / \mathrm{CoFeB}$ tunnel junction, Appl. Phys. Lett., 99(2011), 012502. 


\section{Особенности наблюдения неоднородностей намагниченности на поверхности тонких магнитных пленок в $\mathrm{Ta} / \mathrm{CoFeB} / \mathrm{MgO} / \mathrm{CoFeB} / \mathrm{Ta}$ многослойных структурах}

Николай А. Дюжев

Анатолий $\Phi$. Попков

Максим А. Махиборода Глеб Д. Демин

Александр М. Козьмин

Максим Ю.Чиненков

Национальный исследовательский университет электронных технологий (МИЭТ) Шокина, 1, Москва, Зеленоград, 124498

Россия

\footnotetext{
Представлены результаты исследования неоднородностей намагниченности на поверхности тонких магнитных пленок в структуре многослойного магнитного туннельного перехода (МТП) $\mathrm{Ta} / \mathrm{CoFeB} / \mathrm{MgO} / \mathrm{CoFeB} / \mathrm{Ta}$ с помощъю высокочувствительных зондов МСМ. Проведено микромагнитное моделирование магнитной динамики в СоFеВ магнитном слое при наведении внешнего магнитного поля величиной 0.5 Тл с использованием программного пакета титах3. Найдены области существования магнитных вихрей и доменных стенок в СоFеВ магнитной пленки, а также измерены толщины доменных стенок в нанометровом масштабе.
}

Ключевые слова: магнитная силовая микроскопия, тонкие магнитные пленки, магнитные домены, магнитный туннелъный переход. 